\title{
MADS-Box Genes Are Associated with the Petaloidy/Sepaloidy of Stamens in Cytoplasmic Male Sterile Brassica
}

\author{
Gopal Saha $^{1 \dagger}$, Jong-In Park ${ }^{1 \dagger}$, Hoytaek Kim ${ }^{1}$, Kwon-Kyoo Kang ${ }^{2}$, Yong-Gu Cho ${ }^{3}$, Ill-Sup Nou ${ }^{1 *}$ \\ ${ }^{1}$ Department of Horticulture, Sunchon National University, Suncheon 57922, Korea \\ ${ }^{2}$ Department of Horticulture, Hankyong National University, Anseong 17579, Korea \\ ${ }^{3}$ Department of Crop Science, Chungbuk National University, Cheongju 28644, Korea
}

\begin{abstract}
MADS-box genes are well known for the ABC model of flower development. In this study, we investigated the expressions of A, B and C functions Brassica rapa MADS-box genes in different Ogura cytoplasmic male sterile (CMS) lines of $B$. juncea, B. oleracea, and their wild types. We observed two APl-like (BjAP1 and BoCAL1), three PISTILLATA-like (PI-like; BjPI1, $B o P I 1$, and BoPI2) and six AGAMOUS-like (AG-like; BjAGL1, BjAGL2, BjAGL3, BjAGL4, BoAGL1, and BoAGL2) genes to be altered their expressions in the CMS B. juncea and $B$. oleracea compared to their wild types. Partial and complete petaloidy in the third whorl (stamen) were observed of two CMS B. juncea lines J26 and J27, respectively. Besides, a sepaloidy structure was evident in the third whorl of CMS B. oleracea line 25053. Altered expressions of BjAP1 and BjPI1 in the fourth whorl (pistil) can be correlated with curved and robust stature of pistils in CMS B. juncea. Furthermore, an in silico protein interaction analysis revealed that AP-like, $P I$-like, and AG-like proteins are in close association with different MADS-box proteins and LEAFY (LFY), UNUSUAL FLORAL ORGANS (UFO), SEUSS (SEU), LEUNIG (LUG) for different floral organ development. We suggest that expressions of MADS-box genes might be dependent on mitochondrial signaling for cytoplasmic homeosis in CMS B. juncea and B. oleracea. The expression dataset on $\mathrm{A}, \mathrm{B}$, and C functions MADS-box genes of CMS and wild type B. juncea and B. oleracea presented in this study might be useful for the development of CMS in different Brassica species.
\end{abstract}

Keywords CMS, MADS-box, Petaloidy, Sepaloidy, Brassica juncea, Brassica oleracea

\section{INTRODUCTION}

Development of floral organs is controlled by the homeotic genes in higher plants which have been studied widely in dicotyledonary plants, especially Arabidopsis and Antirrhinum (Theissen and Saedler 1999; Theissen 2001). Normally, a complete flower from dicotyledonary plant has four whorl structures, where sepals are in the first whorl, petals in the second whorl, stamens in the third whorl and carpels inside of flower. Based on the $A B C$ model of floral organ development, involvement of three classes (A, B, and C) of nuclear homeotic genes could explain and predict flower organ families (Davies and Schwarz-Sommer 1994; Ma 1994; Weigel and Meyerowitz 1994). This model has further extended by two other class
D and E genes (Theissen 2001). It is hypothesized that these five classes of genes are associated with their genetic functions through intensive interactions. For specifying of sepals, class-A genes interact with class-E genes. The expressions of class- $\mathrm{A}, \mathrm{B}$, and $\mathrm{E}$ genes determine petals development and the expressions of class- $\mathrm{B}, \mathrm{C}$, and $\mathrm{E}$ determine stamens development, respectively. In addition, the combined actions of class- $\mathrm{C}$ and $\mathrm{E}$ genes transformed into carpels and class-D genes are identified for ovule constructions. The total process is termed as nuclear homeosis (Kramer et al. 1998, 2004; Krizek and Fletcher 2005; Hernández-Hernández et al. 2007).

Cytoplasmic male sterility (CMS) is a maternally inherited trait where plants fail to produce viable pollen. CMS exists in many plant species and they have been

Received January 25, 2016; Revised February 6, 2016; Accepted February 11, 2016; Published February 28,2016

*Corresponding author Ill-Sup Nou, nis@sunchon.ac.kr, Tel: +82-61-750-3249, Fax: +82-61-750-3208

${ }^{\dagger}$ These authors contributed equally to this paper as co-first authors. 
exploited widely for hybrid production. Genetic research gave the evidences that CMS is often related with unusual open reading frames found in mitochondrial genomes, and in many cases, its male sterility can be restored specifically by nuclear-encoded, fertility restorer genes (Wise and Pring 2002; Brown et al. 2003; Desloire et al. 2003; Koizuka et al. 2003).

According to the abortive stage of pollen there are different types of CMS and they exhibit different CMS-related abnormalities in flower morphology (Linke and Börner 2005). Striking alterations in flower morphology were observed in CMS tobacco (Zubko et al. 2001), CMS wheat (Murai et al. 2002), CMS carrot (Linke et al. 2003) and CMS stem mustard (Yang et al. 2008).

Any kind of mutations or rearrangements in the transcription of these nuclear homeotic genes can lead to differences in the four whorl structures of a flower. A certain type of flower organ is replaced by others (Coen and Meyerowitz 1991; Mandel et al. 1992). There are several reports on mitochondrial mutant and CMS system. The nuclear MADS-box genes, such as AP3-like, GLOBOSA-like (GLO-like), and DEFICIENS-like (DEF-like), were found to be transcriptionally down-regulated and involved in this kind of alteration (Zubko et al. 2001; Murai et al. 2002; Linke et al. 2003; Teixeira et al. 2005). This phenomenon is termed as cytoplasmic homeosis. In cytoplasmic homeosis, rearrangement or replacement of the mitochondrial genome is evident which alters the expressions of nuclear homeotic genes or genes related to homeotic functions (Zubko 2004). Most studies of cytoplasmic homeosis were focused on the CMS systems.

Wild Brassica species are the source of a vast cytoplasmic variability for production of alloplasmic male sterile lines, and therefore, they have great importance in case of breeding (Prakash et al. 1995; Banga and Banga 1998). This genetic variability of Brassica cytoplasm is essential to preserve and enlarge the cytoplasmic diversity in order to afford breeders with new and improved CMS systems and get rid of the possible problem of epidemic diseases (Cardi and Earle 1997). There is report that CMS in Brassica napus has been conferred by alien cytoplasm, such as the Ogura cytoplasm of radish (Ogura 1968), B. tournefortii or the B. oxyrrhima cytoplasm (Liu et al. 1996;
Banga and Banga 1998) or by endogenous cytoplasm like the polima or nap cytoplasm from B. napus (Li et al. 1998; Brown 1999). The Ogura cytoplasm also confers male sterility to B. juncea (Labana and Banga 1989) and 'CMS juncea' promotes CMS in B. napus (Pradham et al. 1991; Liu et al. 1996). And, CMS in B. oleracea was developed by the CMS B. juncea cytoplasm from B. rapa through protoplast fusion (Cardi and Earle 1997).

In this study, we carried out expression analysis of different MADS-box homeotic genes in Ogura CMS lines of B. juncea and B. oleracea. We also made use of their wild types to study the expression of the same set of genes. We identified candidate MADS-box genes which might be responsible for the conversion of homeotic transformations in the selected CMS lines. We speculate nuclear MADS-box transcription factors subject to mitochondrial retrograde regulation are associated with cytoplasmic homeosis in CMS B. juncea and B. oleracea.

\section{MATERIALS AND METHODS}

\section{Plant materials}

We selected $B$. juncea and $B$. oleracea Ogura CMS lines for the expression analysis of the homeotic genes. Two $B$. juncea Ogura CMS lines J26, J27, and one B. olearacea rapid cycle Ogura CMS line 25053 along with their wild relatives (B. juncea J21 and B. oleracea 25050) were grown in soil culture media in a green house with a dark/light cycle of $8 / 16$ hours at $25^{\circ} \mathrm{C}$ at the Department of Horticulture, Sunchon National University, Korea. For the flower organ study, 100 fresh flower buds were harvested and four floral parts sepals, petals, stamens and pistils were separated and frozen immediately in liquid nitrogen, and stored at $-80^{\circ} \mathrm{C}$ for RNA isolation.

\section{Isolation of nucleic acid and reverse transcription}

Total RNA was isolated from the every whorl of floral organs using an RNeasy mini kit (Qiagen, Hilden, Germany), after which it was treated with RNase-free DNase (Qiagen) for $15 \mathrm{~min}$ at ambient temperature to remove genomic DNA contaminants. Total amount of RNA was determined by ultraviolet spectrophotometry. A reverse transcription 
kit Superscript III (Invitrogen, Carlsbad, CA, USA) was used to transcribe total RNA into cDNA.

\section{Identification of MADS-box genes and in silico analysis}

We selected 20 flower homeotic $B$. rapa MADS-box genes for the expression study in CMS $B$. juncea and $B$. oleracea flower organs based on our previously published dataset (Saha et al. 2015). Polymerase chain reaction (PCR) primer information was also collected from our published data. An online tool STRING 10 (http://string-db.org/) was used to predict association and interaction of MADS-box proteins with other proteins.

\section{Expression analysis of MADS-box genes}

Samples from every whorl of $B$. juncea and B. oleracea flowers were collected from CMS lines and their wild types as well. Reverse transcription (RT)-PCR was conducted using an AMV one step RT-PCR kit (Takara Bio Inc., Shiga, Japan). Specific primers for all genes as mentioned in Supplementary Table 1 were used in RT-PCR. B. rapa Actin (BrActin) primer was used as control for RT-PCR expression analysis (Supplementary Table 1, available online only). PCR was conducted using $50 \mathrm{ng}$ cDNA from the plant and flower organs as templates in master mixes composed of $20 \mathrm{pmol}$ each primer, $150 \mu \mathrm{M}$ each $\mathrm{dNTP}, 1.2$ $\mathrm{U}$ Taq polymerase, $1 \times$ Taq polymerase buffer and double-distilled $\mathrm{H}_{2} \mathrm{O}$ diluted to a total volume of $20 \mu \mathrm{l}$ in $0.5-\mathrm{ml}$ PCR tubes. The samples were subjected to the following conditions: pre-denaturing at $94^{\circ} \mathrm{C}$ for 5 minutes, followed by 30 cycles of denaturation at $94^{\circ} \mathrm{C}$ for 30 seconds, annealing at $55^{\circ} \mathrm{C}$ for 30 seconds and extension at $72^{\circ} \mathrm{C}$ for 45 seconds, with a final extension for 5 minutes at $72^{\circ} \mathrm{C}$.

\section{RESULTS}

\section{Flower phenotypes of CMS B. juncea and B. oleracea and their wild types}

An interesting alteration in the morphology of floral organs of CMS B. juncea lines (J26 and J27) was observed. Flowers of CMS B. juncea reduced in size compared to their wild types (Fig. 1A). Specifically, the size of the petals was dramatically reduced. Besides, size and shape of the pistils in CMS B. juncea were also changed. Pistils in CMS J26 became larger in size and severely curved with a deformed stigma, whereas the pistils in case of CMS J27 showed only larger stature keeping other features intact. CMS B. juncea exhibited single and mixed homeotic transformation of stamens. In CMS J26, stamens have been transformed into a mixed structure where both whorl two (stamen) and whorl three (petal) organs were sticking. And, in J27 CMS flowers whorl three (stamen) completely transformed into whorl two i.e., petaloidy (Fig. 1B). Besides, B. oleracea 25053 CMS line also exhibited reduced flower size with severely curved pistils compared to its wild type. More importantly, a complete homeotic conversion of the whorl three (stamen) into whorl one (sepaloid) with a green appearance has been observed here.

\section{Selection of MADS-box homeotic genes for expression analysis}

Evolutionary relations among different Brassica species revealed that they evolved from a common ancestor following ancient genome triplication along with numerical and structural chromosomal changes that occurred 7.9-14.6 million years ago (MYA) (Lysak et al. 2005). The core oleracea lineage that gave rise to $B$. oleracea and $B$. rapa originated $\approx 3$ MYA (Arias et al. 2014). Besides, $B$. juncea is an amphidiploid, evolved from $B$. rapa and $B$. nigra which contained the intact Brassica A genome. Moreover, data from molecular studies suggest that $B$. rapa was the cytoplasmic donor of $B$. juncea. Considering the evolutionary relationship, we were highly optimistic to find constitutive and corresponding expressions of $B$. rapa MADS-box (BrMADS-box from here on) homeotic genes in different $B$. juncea and B. oleracea lineage.

MADS-box genes are the major components of the well-known ' $\mathrm{ABC}$ ' model where they perform core functions in flower organ development of higher plants (Ma and dePamphilis 2000). We identified and characterized MADS-box genes relating to $\mathrm{A}, \mathrm{B}$, and $\mathrm{C}$ functions in the $B$. rapa genome (Saha et al. 2015). From our published dataset, we identified 20 BrMADS-box genes those showed constitutive expression patterns in flowers of $B$. rapa, have been considered here to check their expressions in CMS 
(A)
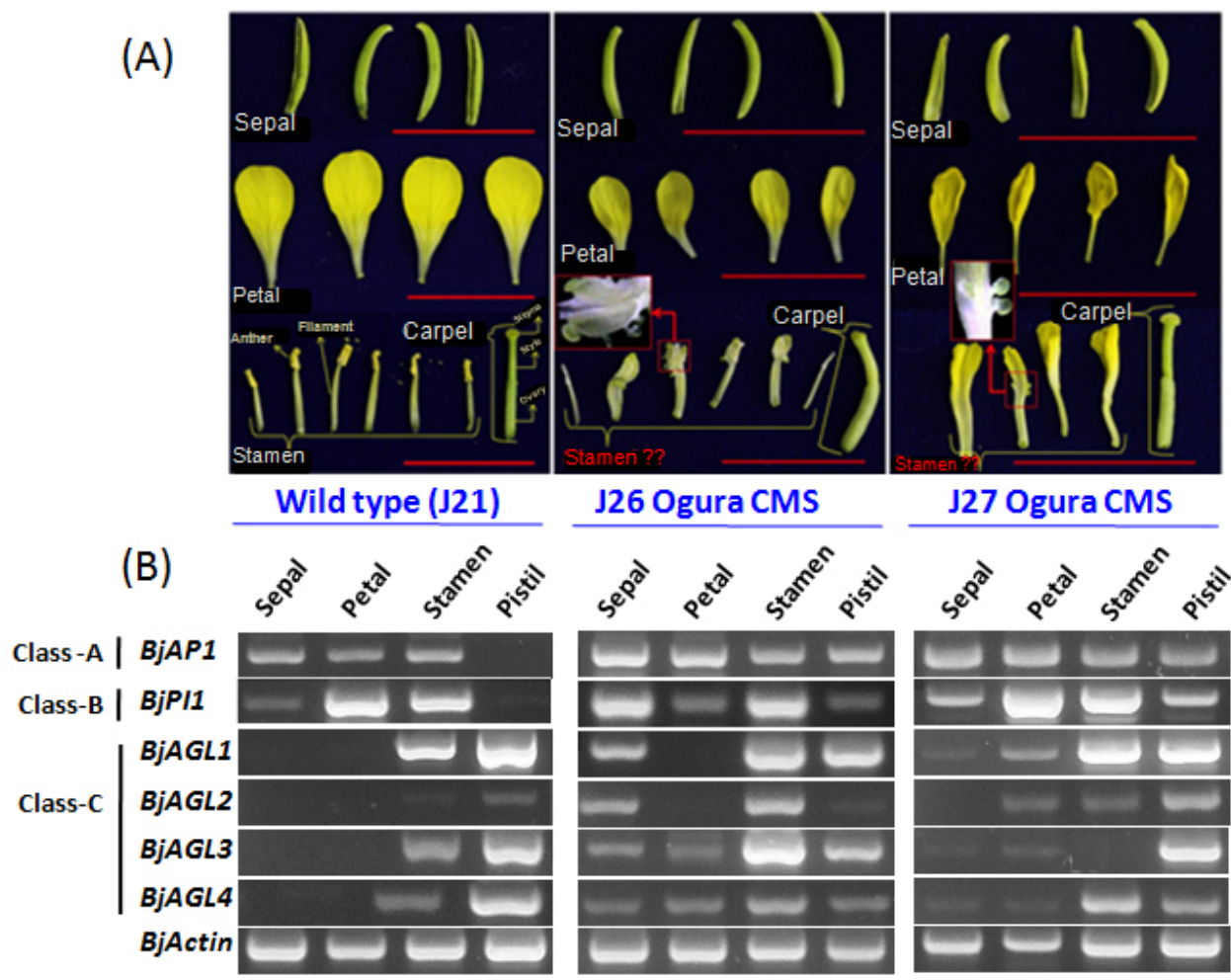

Fig. 1. A representation of Brassica juncea wild type (J21) and cytoplasmic male sterility (CMS; J26 \& J27) phenotypes with expression profiles of A, B, and C class MADS-box genes in the four flower whorls. (A) Showing four flower organs (whorl 1-4; sepal, petal, stamen, and pistil) in wild type B. juncea J21 where all the organs showed regular patterns. Besides, CMS J26 phenotypes showed a reduced petal, sticking stamen, and comparatively large curved pistil. And, CMS J27 phenotypes are presented with the smallest petals, petaloid stamen, and a large pistil. (B) Showing comparative expressions of A (BjAP1), B (BjPI1), and C (BjAGL1, BjAGL2, BjAGL3, and BjAGL4) class MADS-box genes in CMS lines and their wild type.

lines of B. juncea, B. oleracea, and their wild relatives (Supplementary Fig. 1, available online only). All these genes were under the MADS-box family due to their conserved MADS-box domain in the N-terminal regions (Saha et al. 2015). We selected two BrMADS-box genes from AGL15-like subfamily (BrMADS3 and 5), three from GGM13-like (BrMADS26, 27, and 28), three under GLO-like (BrMADS29, 30, and 31), two from DEF-like (BrMADS32 and 33), seven MADS-box genes from AGAMOUS-like (BrMADS53, 54, 55, 56, 57, 59, and 60) and three genes from SQUA-like subfamily (BrMADS61, 63 , and 70). Based on the expression patterns of these flower expressed genes, we focused on eight MADS-box genes (BrMADS63, BrMADS70, BrMADS30, BrMADS31, BrMADS53, BrMADS55, BrMADS57, and BrMADS59) from $\mathrm{A}, \mathrm{B}$, and $\mathrm{C}$ category which had constitutive expression patterns in different flower organs of B. juncea and B. oleracea Ogura CMS lines including their wild types (Table 1).

\section{Expression analysis of MADS-box homeotic genes in CMS B. juncea}

In CMS B. juncea, we found homeotic transformation of whorl three (stamen) into other structures (Fig. 1A). To investigate the $\mathrm{ABC}$ model of flower development, here we investigated the expressions of $\mathrm{A}, \mathrm{B}$, and $\mathrm{C}$ functions MADS-box genes in two B. juncea CMS lines J26 and J27 and also in their wild type J21 (Table 1). In the wild type $B$. juncea J21, BjAP1 (APETALA1-like under SQUA-like subfamily) gene from class A was expressed in sepal, petal and stamen (whorl one, two, and three) (Fig. 1B). From the B class gene, BjPI1 (PISTILLATA-like) showed high 
- Plant Breed. Biotech. 2016 (February) 4(1):40 50

Table 1. List of MADS-box genes was used for expression study under 'ABC' model of flower development in cytoplasmic male sterility Brassica juncea and B. oleracea.

\begin{tabular}{clccc}
\hline \hline $\begin{array}{c}\text { Category under } \\
\text { ABC model }\end{array}$ & $\begin{array}{c}\text { Name of MADS-box } \\
\text { subfamily }\end{array}$ & $\begin{array}{c}\text { B. rapa } \\
\text { MADS-box }\end{array}$ & $\begin{array}{c}\text { BrMADS-box homologs } \\
\text { in B. juncea }\end{array}$ & $\begin{array}{c}\text { BrMADS-box homologs } \\
\text { in B. oleracea }\end{array}$ \\
\hline A - Function & APETALA1-like (AP1) & BrMADS63 & BjAP1 & \\
& CAULIFLOWER-like (AP1) & BrMADS70 & & BoCAL1 \\
B - Function & PISTILLATA-like & BrMADS30 & & BoPI1 \\
& PISTILLATA-like & BrMADS31 & BjPI1 & BoPI2 \\
C - Function & AGAMOUS-like & BrMADS53 & BjAGL1 & BoAGL1 \\
& AGAMOUS-like & BrMADS55 & BjAGL2 & \\
& AGAMOUS-like & BrMADS57 & BjAGL3 & \\
& AGAMOUS-like & BrMADS59 & BjAGL4 & BoAGL2 \\
\hline
\end{tabular}

expression in petals and stamens (whorl two and three) with a very low level expression in the sepals (whorl one). And, under class $\mathrm{C}$, four AGAMOUS-like genes (BjAGL1, 2,3 , and 4) showed their expressions exclusively in whorl three (stamens) and four (pistils). Expression patterns of these genes in B. juncea support the $\mathrm{ABC}$ model of flower development. However, their expressions were found to be altered in the CMS B. juncea lines. BjAPI in CMS J26 was additionally expressed the pistils besides sepals, petals and stamens. In case of BjPII, we found a differential expression patterns in all the flower whorls. Specifically, in J26 CMS line, expressions of BjPII in sepals and petals were altered compared to its wild type. Expression patterns of four AGAMOUS-like genes in CMS J26 and $\mathrm{J} 27$ were altered dramatically. BjAGL1 expressed in sepals of J26 and sepals and petals of $\mathrm{J} 27$, in addition to stamen and pistil expressions. BjAGL2 showed expressions mainly in the sepals and stamens of J26. Besides, in CMS J27, BjAGL2 was expressed in the three whorls except sepals. Two other $A G$-like genes, BjAGL3 and BJAGL4, showed expressions in all the flower whorls of J26 flower, where transcript levels of both these genes were altered compared to wild type J21. In case of J27 CMS, BjAGL3 did not show any expression in stamens rather it expressed in the sepals and petals beside pistils. But, expression of BjAGL4 was observed in all the four flower whorls of CMS J27.

\section{Expression analysis of MADS-box homeotic genes CMS B. oleracea}

In B. oleracea CMS 25053, a complete homeotic conversion of whorl three (stamen) into whorl one (sepaloid) has been observed (Fig. 2A). To understand the reasons behind this alteration, we closely investigated expression patterns of $\mathrm{A}, \mathrm{B}$, and $\mathrm{C}$ functions MADS-box genes in CMS B. oleracea and compared their expressions with wild type 25050 . In the wild type $B$. oleracea, BoCAL1, which is an A- function MADS-box gene (CAULIFLOWER-likelAPl-like), showed expression in the whorl one, two and three. On the other hand, in Ogura CMS 25053, it showed expression with higher transcript abundance in whorl one (sepal) and two (petals) and which has been drastically reduced in whorl three (stamen). Additionally, it expressed at lower level in the whorl four (pistil). From the B-function gene, we found two PI-like genes BoPI1 and BoPI2 to be expressed constitutively between the CMS line and its wild type. In the wild type $B$. oleracea, BoPIl exhibited expressions mainly in the whorl two and three. These expression patterns have been changed dramatically in the CMS line, where the transcript level of BoPIl has been increased a bit more in the whorl two (petal). Conversely, expression of this gene in whorl three (stamen) drastically reduced nearly to zero. Furthermore, it expressed in the whorl one (sepal) and whorl four (pistil) of CMS B. oleracea. Besides, another PI-like Bfunction gene BoPI2 in wild type showed very high expressions in whorl one, two and three compared to whorl four. In CMS line, expression of BoPI2 in the whorl two and four found to be increased, which have been reduced in whorl one and three. Finally, from the C-function $A G$-like gene, we closely compared expression of two genes 
(A)
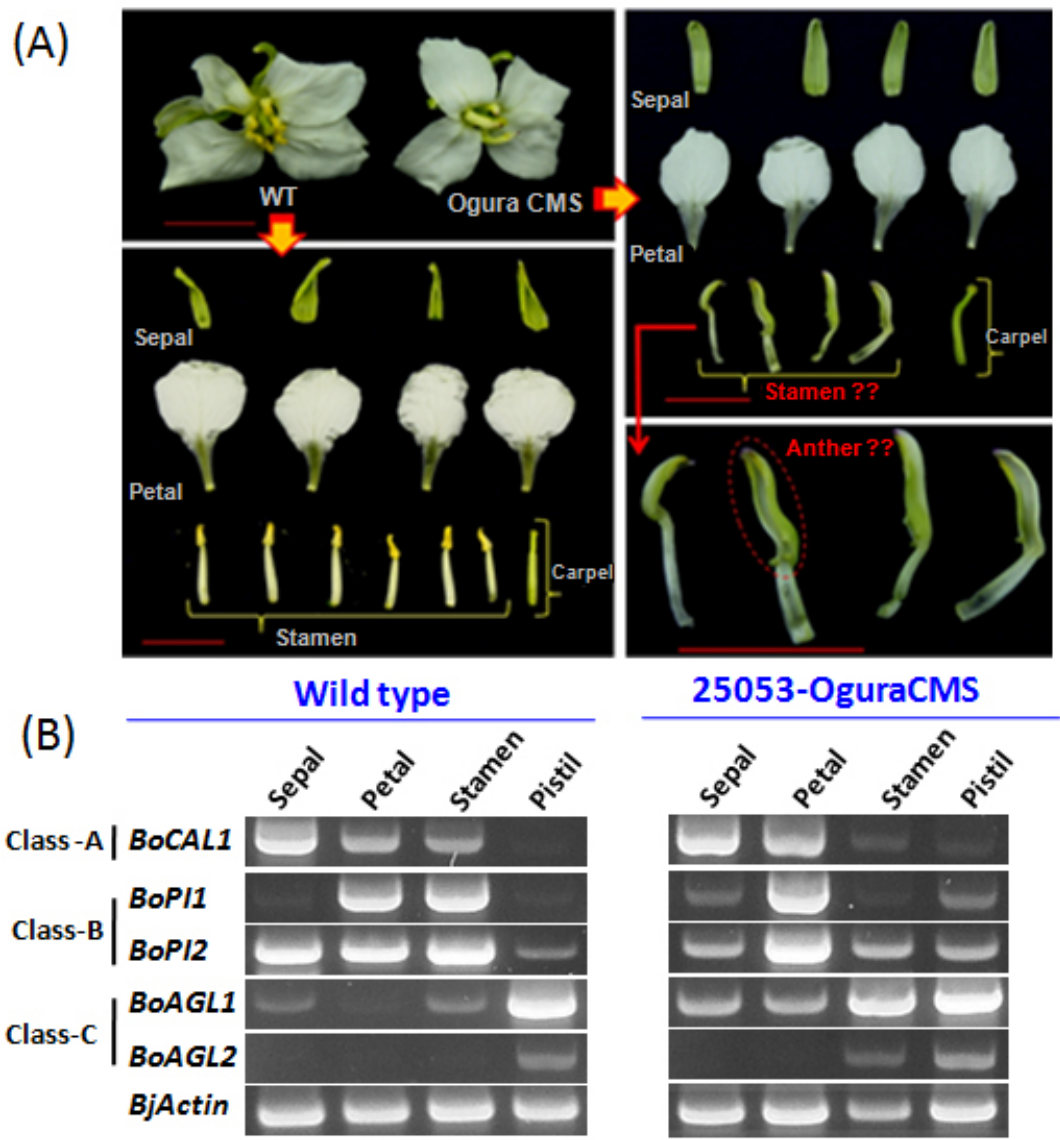

Fig. 2. A representation of Brassica oleracea wild type (25050) and cytoplasmic male sterility (CMS) 25053 phenotypes with expression profiles of A, B, and C class MADS-box genes in the four flower whorls. (A) Showing four flower organs (whorl 1-4; sepal, petal, stamen, and pistil) in wild type B. oleracea, where all the organs showed regular patterns. Besides, CMS 25053 phenotypes showed comparatively lager sepals, sepaloid stamens, and a curved pistil. (B) Showing comparative expressions of A (BoCAL1), B (BoPI1 and BoPI2), and C (BoAGL1 and BoAGL2) class MADS-box genes in CMS line and its wild type.

(BoAGL1 and BoAGL2) between the CMS B. oleracea and its wild type. BoAGL1 in wild type showed highest expression in the whorl four besides very low level expressions in the whorl one and three. Interestingly, its whorl three expression in the CMS line surprisingly increased along with greater increment of its transcripts in whorl one and two as well. Another $A G$-like gene BoAGL2 expressed exclusively in the whorl four of wild $B$. oleracea which has also found to be expressed in the whorl three in addition to the whorl four of CMS B. oleracea.

\section{Analysis of interactions among homeotic MADS-box proteins}

We constructed a protein association network among A,
$\mathrm{B}$, and $\mathrm{C}$ functions BrMADS-box proteins (predicted close homologs in B. juncea and B. oleracea) and related Arabidopsis proteins using online software String 10.0 (Fig. 3). We found our query MADS-box proteins (BjAP1, BoCAL1, BjPI1, BoPI1, BoPI2, BjAGL1, BjAGL2, BjAGL3, BjAGL4, BoAGL1, and BoAGL2) were in stronger association with other homeotic proteins including $\mathrm{A}, \mathrm{B}$ and $\mathrm{C}$ functions MADS-box proteins. We found that the A function proteins (BjAP1 and BoCAL1) interacted with SHORT VEGETATIVE PHASE (SVP) and AGL24. Besides, three B function proteins BjPI1, BoPI1, and BoPI2 (PI-like) exhibited stronger association with the AP1/2/3, LEAFY (LFY), and UNUSUAL FLORAL ORGANS (UFO). And, we observed six AGAMOUS-like 


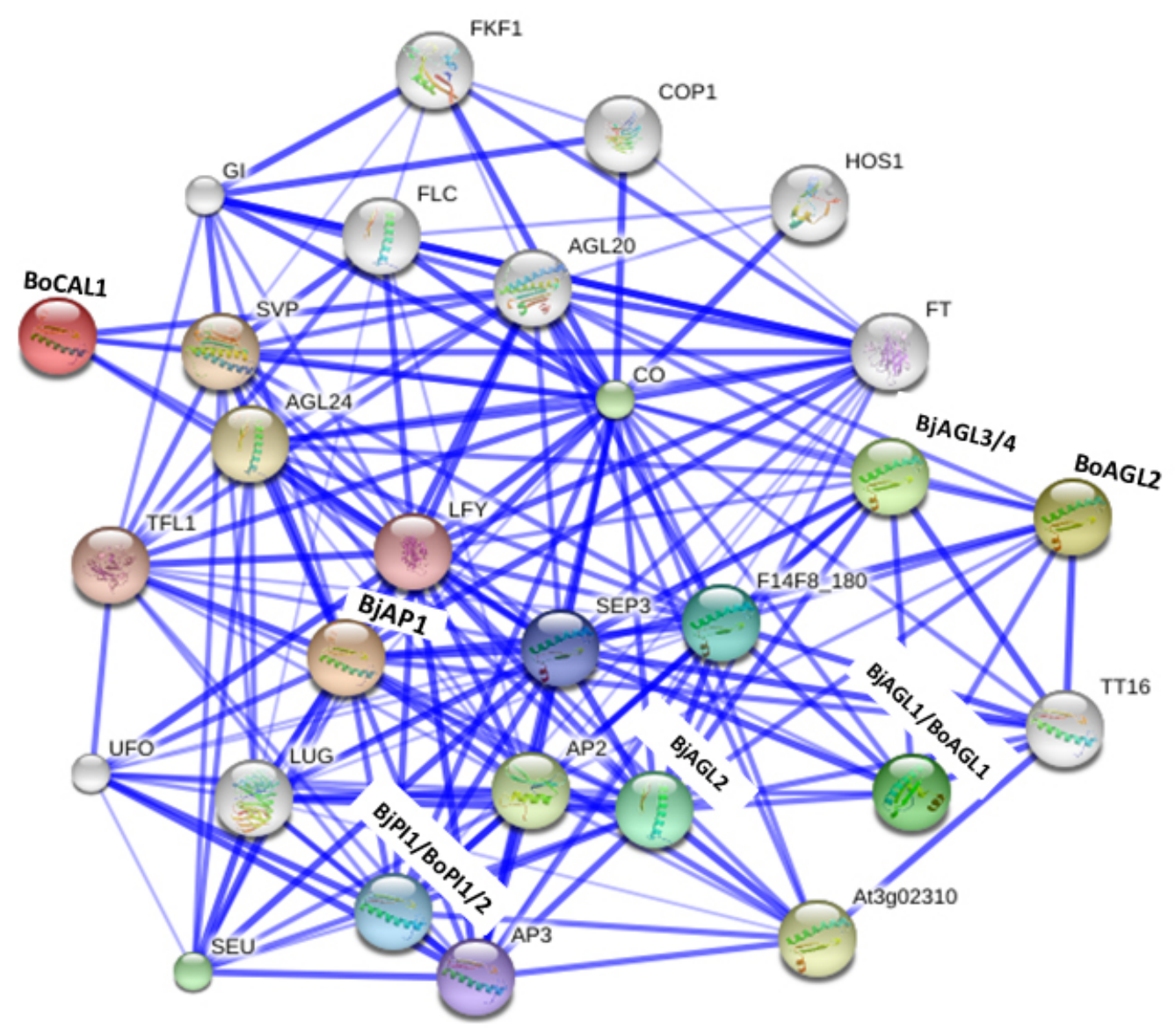

Fig. 3. Interaction network among predicted Brassica juncea and B. oleracea homeotic MADS-box proteins (marked in bold letter) and related functional partners based on their close Arabidopsis counterpart proteins. Stronger associations are represented by thicker lines.

C function proteins BjAGL1, BjAGL2, BjAGL3, BjAGL4, BoAGL1, and BoAGL2 interacted strongly with AP1/2/3, TRANSPARENT TESTA16 (TT16), PI-like (BjPI1, BoPI1, and PoPI2), SEUSS (SEU), and LEUNIG (LUG) flower organ development related proteins. We speculate these predicted functional partners of $\mathrm{A}, \mathrm{B}$, and $\mathrm{C}$ functions MADS-box proteins might play important roles in specifying different flower whorls in $B$. juncea and $B$. oleracea.

\section{DISCUSSION}

CMS is an outcome of miscoordination between foreign nuclear and cytoplasmic gene products (Aviv and Galun 1980). These alterations are primarily caused by mutations, rearrangements, and/or recombinations inside the mitochondrial genome (Carlsson and Glimelius 2011). And, changes in mitochondrial genes are associated with the development of male sterility. Normally, homeotic transformation of floral organs can be observed in the male sterile condition (Linke and Börner 2005). Only mitochondrial factors do not control reproductive development in plants. We speculate there might some signaling activities from mitochondria to nucleus could be involved in the homeotic transformation of CMS floral organs and it happens through set of CMS-inducing genes.

In this study, phenotypic variations in floral organization and stamens have been observed in the Ogura CMS lines of B. juncea (J26 and J27) and B. oleracea (25053). Similar types of variations were also observed in some Brassica alloplasmic cytoplasm, e.g., the Raphnnus/Ogura (Bannerot 
et al. 1974), species cross B. nigra (L) Koch/B. oleracea $\mathrm{L}$. (Pearson 1972) and B. napus with Arabidopsis cytoplasm (Leino et al. 2003). In higher plants, flower development mechanism has been interpreted through the functioning of $\mathrm{ABC}$ model, where mutation and over-expression of these genes might lead to homeotic transformations in the flower organization (Zubko 2004). In this study, we investigated the expressions of APl-like, PI-like, and AG-like MADS-box genes where they expressed absolutely in their whorls of floral organ as per $\mathrm{ABC}$ model in the wild types of B. juncea and B. oleracea (Fig. 1, 2). However, their reduced/altered transcript levels in the CMS lines could possibly involved in the development of petaloid and sepaloid stamens.

According to $\mathrm{ABC}$ flower development model, nuclear homeotic genes are expected to be expressed organspecifically in the individual flower whorls of normal plants. Expression analysis of AP1-like (BjAP1 and BoCAL1), PI-like (BjPI1, BoPI1, and BoPI2) and AG-like (BjAGL1, BjAGL2, BjAGL3, BjAGL4, BoAGL1, and $B o A G L 2)$ genes in CMS B. juncea (J26 and J27) and $B$. oleracea (25053) revealed their ectopic expressions, of which $A P$-like and AG-like genes were unexpectedly expressed in pistils and petals, respectively. These types of homeotic conversions have also been evident in CMS $B$. juncea var. tumida Tsen et Lee (stem mustard) and B. napus (Geddy et al. 2004; Yang et al. 2008). In B. juncea CMS $\mathrm{J} 26$ and $\mathrm{J} 27$, pistil expressions of AP1-like and PI-like genes can be correlated with the phenotypes, where they produced severely curved and robust pistils. Besides, altered expressions of PI-like gene in the second whorl might be responsible for the reduced growth of petals. These phenomenons have also been observed in case of AP3 and PI mutant phenotype of Arabidopsis, where stamens were fully replaced by carpels and petals were reduced (Bowman et al. 1989; Farbos et al. 2001). Meur et al. (2006) also reported about the modification of stamens into petals in CMS Ogura B. juncea. And interestingly, in the case of CMS B. oleracea APl-like and PI-like expressions have almost abolished in stamens, instead they showed increased transcript levels in the sepals and petal. Finally, a sepaloid phenotype in the third whorl of this CMS was found (Fig. 2). This phenomenon is very rare among the features of other CMS in higher plants. In mutant Petunia, Van Der Krol and Chua (1993) reported sepaloid stamens with normal stamens in the inner two whorls. In a nut shell, alterations in the functions of A, B, and $\mathrm{C}$ class genes in the CMS B. juncea and B. oleracea might be the underlying causes for the development of aberrant flowers. And, we speculate that two different phenotypes like petaloidy and sepaloidy in B. juncea and $B$. oleracea Ogura CMS lines might be due to differential interaction effects between mitochondrial genes and different- A function (AP-like) nuclear MADS-box genes.

On the other hand, a strong association was evident among AP1, LFY and UFO proteins in Sasaki et al. (2012) study, which regulates expression of B class genes in Arabidopsis. In this study, we conducted an in silico protein interaction study using string database which also revealed strong interactions among AP1, LFY, and UFO proteins (Fig. 3). Moreover, interactions among AG-like, SEU and LUG proteins have been reported in Frank et al. (2002) study, where they demonstrated that SEU interacts together with APETALA2 and LEUNING to repress AGAMOUS expression. In conclusion, CMS $B$. juncea and $B$. oleracea showed partial and complete homeotic transformation of stamens into petaloid and sepaloid structures. We speculate that in the CMS line, expressions of AP1-like (BjAP1 and BoCAL1), PI-like (BjPI1, BoPI1, and BoPI2) and AG-like (BjAGL1, BjAGL2, BjAGL3, $B j A G L 4, B o A G L 1$, and BoAGL2) genes those encode MADS-box transcription factor might be influenced by mitochondrial genome and thus, a retrograde signalling between mitochondria and nucleus might trigger ectopic expressions of the floral homeotic genes $(\mathrm{A}, \mathrm{B}$, and $\mathrm{C}$ ) in different whorls. We assume that expressions data related to floral organ development of wild and CMS B. juncea and B. oleracea, presented in this study might be useful for undertaking specific investigation to uncover the mechanism of floral homeotic conversions in different CMS Brassica.

\section{ACKNOWLEDGEMENTS}

This research was jointly supported by Basic Science Research Program through the National Research Foun- 
dation of Korea (NRF) funded by the Ministry of Education, Science and Technology (2012R1A1A2044500) and Golden Seed Project (Center for Horticultural Seed Development, No. 213003-04-3-SB110, 213003-04-3-SB420), Ministry of Agriculture, Food and Rural Affair (MAFRA), Ministry of Oceans and Fisheries (MOF), Rural Development Administration (RDA) and Korea Forest Service (KFS).

\section{REFERENCES}

Van Der Krol AR, Chua NH. 1993. Flower development in Petunia. Plant Cell 5: 1195-1203.

Arias T, Beilstein MA, Tang M, McKain MR, Pires JC. 2014. Diversification times among Brassica (Brassicaceae) crops suggest hybrid formation after 20 million years of divergence. Am. J. Bot. 101: 86-91.

Aviv D, Galun E. 1980. Restoration of fertility in cytoplasmic male sterile (CMS) Nicotiana Sylvestris by fusion with X-irradiated N. tabacum protoplasts. Theor. Appl. Genet. 58: $121-127$

Banga SK, Banga SS. 1998. Attempts to develop fertility restorers for oxy CMS in crop Brassica, p. 305-309. In: T. Grégoire, A.A. Monteiro (eds.). Proc. of ISHS International Symposium on Brassicas. Rennes, France.

Bannerot H, Boulidard L, Cauderon Y, Tempe J. 1974. Transfer of cytoplasmic male sterility from Raphanus sativus to Brassica oleracea. Proc. Eucarpia Meet. Cruciferae Crop Sect. 25: 52-54.

Bowman JL, Smyth DR, Meyrowitz EM. 1989. Genes directing flower development in Arabidopsis. Plant Cell 1: $37-52$.

Brown GG, Formanová N, Jin H, Wargachuk R, Dendy C, Patil P, et al. 2003. The radish Rfo restorer gene of Ogura cytoplasmic male sterility encodes a protein with multiple pentatricopeptide repeats. Plant J. 35: 262-272.

Brown GG. 1999. Unique aspects of cytoplasmic male sterility and fertility restoration in Brassica napus. J. Hered. 90: 351-356.

Cardi T, Earle ED. 1997. Production of new CMS Brassica oleracea by transfer of cytoplasm from $B$. rapa through protoplast fusion. Theor. Appl. Genet. 94: 204-212.

Carlsson J, Glimelius K. 2011. Cytoplasmic male-sterility and nuclear encoded fertility restoration. Plant Mitochond. 1: 469-491.
Coen ES, Meyerowitz EM. 1991. The war of the whorls: genetic interactions controlling flower development. Nature 353: 31-37.

Davies B, Schwarz-Sommer Z. 1994. Control of floral organ identity by homeotic MADS-box transcription factors, $\mathrm{p}$. 235-258. In: L. Nover (ed.). Plant promoters and transcription factors. Springer, Berlin, Heidelberg, New York, NJ.

Desloire S, Gherbi H, Laloui W, Marhadour S, Clouet V, Cattolico L, et al. 2003. Identification of the fertility restoration locus, $R f o$, in radish, as a member of the pentatricopeptide-repeat protein family. EMBO Rep. 4: 588-594.

Farbos I, Mouras A, Bereterbide A, Glimelius K. 2001. Defective cell proliferation in the floral meristem of alloplasmic plants of Nicotiana tabacum leads to abnormal floral organ development and male sterility. Plant J. 26: 131-142.

Franks RG, Wang C, Levin JZ, Liu Z. 2002. SEUSS, a member of a novel family of plant regulatory proteins, represses floral homeotic gene expression with $L E U N I G$. Development 129: 253-263.

Geddy R, Mahé L, Brown GG. 2005. Cell-specific regulation of a Brassica napus CMS-associated gene by a nuclear restorer with related effects on a floral homeotic gene promoter. Plant J. 41: 333-345.

Hernández-Hernández T, Martínez-Castilla LP, AlvarezBuylla ER. 2007. Functional diversification of B MADS-box homeotic regulators of flower development: Adaptive evolution in protein-protein interaction domains after major gene duplication events. Mol. Biol. Evol. 24: 465-481.

Koizuka N, Imai R, Fujimoto H, Hayakawa T, Kimura Y, Kohno-Murase J, et al. 2003. Genetic characterization of a pentatricopeptide repeat protein gene, orf687, that restores fertility in the cytoplasmic male-sterile Kosena radish. Plant J. 34: 407-415.

Kramer EM, Dorit RL, Irish VF. 1998. Molecular evolution of genes controlling petal and stamen development: duplication and divergence within the APETALA3 and PISTILLATA MADS-box gene lineages. Genetics 149: 765-783.

Kramer EM, Jaramillo MA, Di Stilio VS. 2004. Patterns of gene duplication and functional evolution during the diversification of the AGAMOUS subfamily of MADS 
box genes in angiosperms. Genetics 166: 1011-1023.

Krizek BA, Fletcher JC. 2005. Molecular mechanisms of flower development: an armchair guide. Nat. Rev. Genet. 6: 688-698.

Labana KS, Banga SK. 1989. Transfer of Ogura cytoplasmic male sterility of Brassica napus into genetic background of Brassica juncea. Crop Improv. 16: 82-83.

Leino M, Teixeira R, Landgren M, Glimelius K. 2003. Brassica napus lines with rearranged Arabidopsis mitochondria display CMS and a range of developmental aberrations. Theor. Appl. Genet. 106: 1156-1163.

Li XQ, Jean M, Landry BS, Brown GG. 1998. Restorer genes for different forms of Brassica cytoplasmic male sterility map to a single nuclear locus that modifies transcripts of several mitochondrial genes. Proc. Natl. Acad. Sci. U.S.A. 95: 10032-10037.

Linke B, Börner T. 2005. Mitochondrial effects on flower and pollen development. Mitochondrion 5: 389-402.

Linke B, Nothnagel T, Börner T. 2003. Flower development in carrot CMS plants: mitochondria affect the expression of MADS box genes homologous to GLOBOSA and DEFICIENS. Plant J. 34: 27-37.

Liu JH, Landgren M, Glimelius K. 1996. Transfer of the Brassica tournefortii cytoplasm to B. napus for the production of cytoplasmic male sterile B. napus. Physiol. Plant. 96: 123-129.

Lysak MA, Koch M, Pecinka A, Schubert I. 2005. Chromosome triplication found across the tribe Brassiceae. Genome Res. 15: 516-525.

Ma H, dePamphilis C. 2000. The ABCs of floral evolution. Cell 101: 5-8.

Ma H. 1994. The unfolding drama of flower development: recent results from genetic and molecular analyses. Genes. Dev. 8: 745-756.

Mandel MA, Bowman JL, Kempin SA, Ma H, Meyerowitz EM, et al. 1992. Manipulation of flower structure in transgenic tobacco. Cell 71: 133-143.

Meur G, Gaikwad K, Bhat SR, Prakash S, Kirti PB. 2006. Homeotic-like modification of stamens to petals is associated with aberrant mitochondrial gene expression in cytoplasmic male sterile Ogura Brassica juncea. J. Genet. 85: 133-139.

Murai K, Takumi S, Koga H, Ogihara Y. 2002. Pistillody, homeotic transformation of stamens into pistil-like structures, caused by nuclear-cytoplasm interaction in wheat. Plant J. 29: 169-181.

Ogura H. 1968. Studies on the new male-sterility in Japanese radish with specific reference to the utilization of this sterility towards the practical raising of hybrid seeds. Mem. Fac. Agric. Kagoshima Univ. 6: 39-78.

Pearson OH. 1972. Cytoplasmically inherited male sterility characters and flavor components from the species cross Brassica nigra (L) Koch X Brassica oleracea L. Am. Soc. Hort. Sci. J. 97: 397-402.

Pradham AK, Mukhopadhyay A, Pental D. 1991. Identification of the putative cytoplasmic donor of a CMS system in Brassica juncea. Plant Breed. 106: 204-208.

Prakash S, Kirti PB, Chorpa VL. 1995. Cytoplasmic male-sterility (CMS) systems other than ogu and polima in Brassica: current status. Proc. of the 9th Intl. Rapeseed Conf. Cambridge, UK, pp. 44-48.

Saha G, Park JI, Jung HJ, Ahmed NU, Kayum MA, Chung MY, et al. 2015. Genome-wide identification and characterization of MADS-box family genes related to organ development and stress resistance in Brassica rapa. BMC Genom. 16: 178.

Sasaki K, Yamaguchi H, Aida R, Shikata M, Abe T, Ohtsubo N. 2012. Mutation in Torenia fournieri Lind. UFO homolog confers loss of $T f L F Y$ interaction and results in a petal to sepal transformation. Plant J. 71: 1002-1014.

Teixeira RT, Farbos I, Glimelius K. 2005. Expression levels of meristem identity and homeotic genes are modified by nuclear-mitochondrial interactions in alloplasmic malesterile lines of Brassica napus. Plant J. 42: 731-742.

Theissen G, Saedler H. 1999. The golden decade of molecular floral development (1990-1999): a cheerful obituary. Dev. Genet. 25: 181-193.

Theissen G. 2001. Development of floral organ identity: stories from the MADS house. Curr. Opin. Plant Biol. 4: 75-85.

Weigel D, Meyerowitz EM. 1994. The ABCs of floral homeotic genes. Cell 78: 203-209.

Wise RP, Pring DR. 2002. Nuclear-mediated mitochondrial gene regulation and male fertility in higher plants: Light at the end of the tunnel? Proc. Natl. Acad. Sci. U.S.A. 99: 10240-10242.

Yang JH, Qi XH, Zhang MF, Yu JQ. 2008. MADS-box genes are associated with cytoplasmic homeosis in cytoplasmic male-sterile stem mustard as partially mimicked by specifically inhibiting mtETC. Plant Growth Regul. 56: 
191-201.

Zubko MK, Zubko EI, Ruban AV, Adler K, Mock HP, Misera

SG, et al. 2001. Extensive development and metabolic alteration in cybrids Nicotiana tabacum (+Hyoscyamus niger) are caused by complex nucleo- cytoplasmic incompatatibility. Plant J. 25: 627-639.

Zubko MK. 2004. Mitochondrial tuning fork in nuclear homeotic functions. Trends Plant Sci. 9: 61-64. 